\title{
Total Chemical Synthesis of an Intra-A-Chain Cystathionine Human Insulin Analogue with Enhanced Thermal Stability
}

\author{
John A. Karas, Nitin A. Patil, Julien Tailhades, Marc-Antoine Sani, Denis B. Scanlon, \\ Briony E. Forbes, James Gardiner, Frances Separovic, John D. Wade, * and \\ Mohammed Akhter Hossain*
}

\begin{abstract}
Despite recent advances in the treatment of diabetes mellitus, storage of insulin formulations at $4^{\circ} \mathrm{C}$ is still necessary to minimize chemical degradation. This is problematic in tropical regions where reliable refrigeration is not ubiquitous. Some degradation byproducts are caused by disulfide shuffling of cystine that leads to covalently bonded oligomers. Consequently we examined the utility of the non-reducible cystine isostere, cystathionine, within the A-chain. Reported herein is an efficient method for forming this mimic using simple monomeric building blocks. The intra-A-chain cystathionine insulin analogue was obtained in good overall yield, chemically characterized and demonstrated to possess native binding affinity for the insulin receptor isoform B. It was also shown to possess significantly enhanced thermal stability indicating potential application to next-generation insulin analogues.
\end{abstract}

Diabetes mellitus is a significant global health issue. ${ }^{[1]}$ Insulin remains an essential therapeutic for the treatment of type 1 diabetes mellitus and is often used for the treatment of type 2 diabetes. ${ }^{[2]}$ Numerous insulin analogues have been developed in the past two decades, both long- and shortacting, with several in clinical use. However, together with native insulin, these all undergo chemical degradation and possess a separate propensity to form amyloid fibrils. ${ }^{[3]}$ Both phenomena are accelerated by heat so that insulin formula-

[*] Dr. J. A. Karas, N. A. Patil, Dr. J. Tailhades, Prof. J. D. Wade, Dr. M. A. Hossain

The Florey Institute of Neuroscience and Mental Health

The University of Melbourne

Melbourne, VIC 3010 (Australia)

E-mail: john.wade@florey.edu.au akhter.hossain@unimelb.edu.au

Dr. J. A. Karas, N. A. Patil, Dr. M.-A. Sani, Prof. F. Separovic,

Prof. J. D. Wade, Dr. M. A. Hossain

School of Chemistry, Bio21 Institute, University of Melbourne Melbourne, VIC 3010 (Australia)

Dr. D. B. Scanlon

Department of Chemistry, University of Adelaide

Adelaide, SA 5005 (Australia)

Prof. B. E. Forbes

School of Medicine, Flinders University

Bedford Park, SA 5042 (Australia)

Dr. J. A. Karas, Dr. J. Gardiner

CSIRO, Materials Science and Engineering

Clayton, VIC 3010 (Australia)

(iD)

Supporting information and the ORCID identification number(s) for the author(s) of this article can be found under http://dx.doi.org/10. 1002/anie.201607101. tions require refrigeration. Chemical degradation can manifest itself as de-amidation, oxidation, covalent aggregation and disulfide shuffling and severely impacts upon the formulation and storage of insulin. ${ }^{[4,5]}$ This is problematic for patients living in poorer regions with tropical climates where there is often no consistent access to electricity and refrigeration. ${ }^{[6]}$ Significant levels of impurities in pharmaceutical preparations can affect dosage and, through covalent aggregates, cause immunological side effects. ${ }^{[5]}$ Therefore, development of new insulin analogues with enhanced thermal stability and concomitant increased resistance to chemical degradation is particularly desirable.

A single-chain insulin ${ }^{[7]}$ and an analogue with four disulfide bonds ${ }^{[8]}$ have each been reported to minimize covalent aggregation through introduction of greater structural stability to the insulin molecule which, in turn, imparts greater thermal stability. Replacement of cystine bonds with stable isosteric bridges ${ }^{[9,10]}$ can both prevent S-reduction, disulfide shuffling and polymer formation as well as introduce increased stability although potentially at the risk of loss of functional activity. The efficacy of this approach has been demonstrated in peptides such as oxytocin whereby a selenoether analogue was synthesized and found to have a twenty-fold increase in thermal stability. ${ }^{[11]}$ Therefore, the substitution of cystine with non-reducible mimetics shows much promise for improving the shelf life of insulin formulations.

Insulin possesses a complex structure with 51 residues, two chains and three disulfide bonds (Figure 1 A) and is currently produced by recombinant DNA synthesis ${ }^{[12]}$ because this enables large quantities of the hormone to be produced which is essential for meeting the huge global demand of pharma-

A)

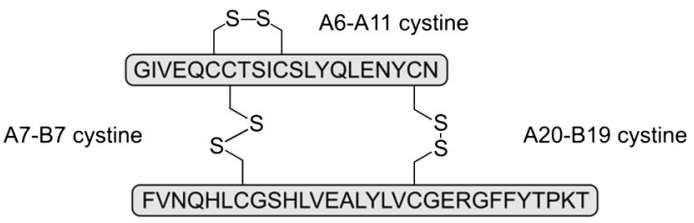

B)

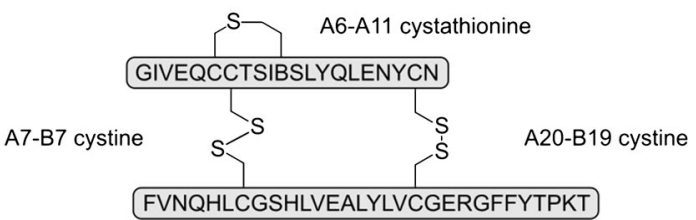

Figure 1. Primary structure of $A$ ) native human insulin; and B) $\mathrm{A}\left[\mathrm{S}-\mathrm{CH}_{2}\right]$ human insulin. $\mathrm{B}=$ homoalaninyl. 
ceutical preparations. However, novel insulin analogues that need to be produced chemically may be commercially feasible as therapeutics for niche markets (such as in regions where thermal stability is an issue) provided that the synthesis is efficient. There are already precedents for the large scale chemical synthesis of other complex peptide-based active pharmaceutical ingredients. ${ }^{[13]}$ Therefore, replacement of the disulfide bonds in insulin with stable isosteres to potentially improve its thermal stability can be viable.

When deciding which disulfide mimetics to use, consideration is given to geometry, toxicity and especially yields since the chemistry should preferably be scalable. Diselenide, ${ }^{[14]}$ selenoether, ${ }^{[11]}$ triazole ${ }^{[15-17]}$ lactam $^{[18,19]}$ and dicarba ${ }^{[20-22]}$ bridges have all been employed as cystine isosteres. However a thioether bridge $\mathrm{e}^{[22-24]}$ was preferred because it more closely mimics the disulfide bond in biologically active peptides and proteins. Although an early attempt to incorporate this moiety to substitute for the intra-A-chain disulfide bond of ovine insulin via solution synthesis was briefly reported, only a trace amount of a highly heterogeneous product was obtained that was not chemically or biologically assessed..$^{[9]}$ For this reason we undertook to develop an efficient process of producing A-chain cystathionine insulin, $\mathrm{A}\left[\mathrm{S}-\mathrm{CH}_{2}\right]$ human insulin (Figure 1B) via solid phase peptide synthesis (SPPS).

The assembly of cystathionine-containing peptides has been studied extensively using tert-butyloxycarbonyl (Boc) or 9-fluorenylmethyloxycarbonyl (Fmoc) SPPS protocols. Desulfurization of a disulfide bond is one method available to form the thioether moiety ${ }^{[25]}$ although this can lead to loss of chiral integrity of the cysteine $\alpha$-carbon. Forming the macrocycle via an $\mathrm{S}_{\mathrm{N}} 2$ reaction between a free thiolate and halogenated side-chain can be performed on the solid support $^{[26]}$ or in solution ${ }^{[11]}$ but this can be low yielding due to steric hindrance and/or hydrolysis of the halide. Incorporation of pre-formed thioether building blocks with orthogonal protection is used widely ${ }^{[22,23,27]}$ and allows macrocyclization to occur via lactamization which is higher yielding. There is the need, however, to synthesize complex building blocks. Alternatively, it is possible to alkylate the free thiol of cysteine with a suitable halogenated amino acid on the solid support. ${ }^{[28,29]}$ A variation of the latter method-whereby the nucleophilic attack occurs in the reverse direction-would only require the synthesis of simple monomeric building blocks and avoid the difficulties of the preceding methods. To achieve this, Fmoc-protected $\gamma$-bromohomoalanine (Fmoc- $\gamma$ $\mathrm{Br}-\mathrm{hAla}-\mathrm{OH})$ was synthesized via a modified version of an existing method (Scheme 1A). ${ }^{[6]}$ A novel cysteine derivative, $\mathrm{N}^{\alpha}$-mono-methoxytrityl-cysteinyl- $\alpha$-allyl ester (Mmt-CysOAll) was also produced efficiently with suitable orthogonal protecting groups (Scheme 1B). A similar conceptual approach has recently been reported by Baell and co-workers in a simple cyclic peptide system. ${ }^{[30]}$ Our work improves on this with respect to the higher yields of the amino acid precursors and application to forming a lactam within a complex peptidic system. The Fmoc SPPS of A[S-CH $\left.\mathrm{CH}_{2}\right]$ human insulin, containing the homoalaninyl-type residue (or $\gamma$-carba moiety) at CysA11, is described herein.

The synthesis of the human insulin A-chain is outlined in Scheme 2. Acylation of the Rink linker via the aspartate side-

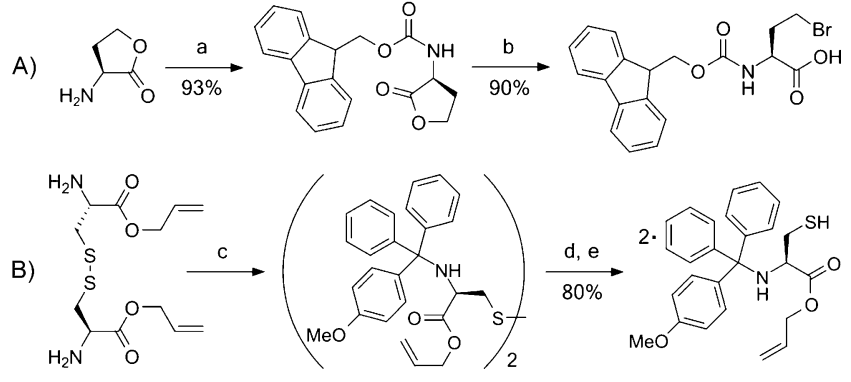

Scheme 1. A) Reagents and conditions: a) 1 equiv. Fmoc-OSu in pyridine, $4 \mathrm{~h}$; b) $\mathrm{HBr} / \mathrm{AcOH}, 4$ h. B) Reagents and conditions: c) 2 equiv. $\mathrm{Mmt}-\mathrm{Cl}, 5$ equiv. DIEA in THF, $4 \mathrm{~h}$; d) 2 equiv. tri- $n$-butylphosphine, 10 equiv. $\mathrm{H}_{2} \mathrm{O}$ in THF, $18 \mathrm{~h}$; e) flash chromatography. Fmoc-OSu= Fmoc succinate; $\mathrm{AcOH}=$ acetic acid; $\mathrm{Mmt}-\mathrm{Cl}=$ mono-methoxytrityl chloride; DIEA = diisopropylethylamine; THF = tetrahydrofuran.

chain on the solid support was performed to avoid epimerization of asparagine during loading. ${ }^{[31]}$ Diphenylmethyl $(\mathrm{Dpm})^{[32]}$ was the preferred protecting group for the A20 thiol since there is insufficient chemoselectivity between trityl (Trt) and mono-methoxytrityl (Mmt) removal. After assembly of I, acylation of the N-terminus with Fmoc- $\gamma$-Br-hAla$\mathrm{OH}$ using carbodiimide activation proceeded efficiently (and avoids lactone formation) to generate II. Introduction of Mmt-Cys-OAll under basic conditions resulted in nucleophilic attack at the $\gamma$-carbon by the thiolate to form the thioether moiety (III). After incorporation of residues A7A10 with acetamidomethyl $(\mathrm{Acm})$ protection at A7 (IV), cleavage of the allyl ester with palladium(0) via allylic transfer ${ }^{[33]}$ was performed followed by Fmoc removal $(\mathbf{V})$. Lactamization was slow, most likely due to steric hindrance on the solid support. Nevertheless, multiple treatments with the acylating reagents to the resin-bound peptide generated VI. No significant cross-linking was observed by reversedphase high performance liquid chromatography (RP-HPLC) or matrix-assisted laser desorption ionization mass spectrometry (MALDI-MS). After treatment with $1 \%$ trifluoroacetic acid (TFA) in dichloromethane (DCM) to cleave the Mmt protecting group from the $\mathrm{N}$-terminus ${ }^{[34]}$ residues A1-A5 were incorporated to form VII. Cleavage from the solid support and concomitant deprotection with a TFA cocktail, followed by purification using RP-HPLC generated the purified A-chain precursor (VIII) in a total yield of $12 \%$ relative to crude material.

The B-chain was synthesized using standard Fmoc SPPS protocols and S-Acm derivatization at B7 (IX). After purification, the peptide was functionalized with the Spyridinesulfenyl (S-Pyr) moiety at B19 followed by a second purification to form $\mathbf{X}$ in $5 \%$ overall yield. Asymmetrical combination of A- and B-chain precursors was then undertaken via displacement of the pyridinesulfenyl leaving group with the $\beta$-thiolate at A20. ${ }^{[35]}$ The synthetic intermediate XI was then purified in a yield of $45 \%$. A large excess of elemental iodine was used to efficiently form the final disulfide bond via oxidative cleavage. ${ }^{[31]}$ After 45 minutes over $80 \%$ of $\mathrm{A}\left[\mathrm{S}-\mathrm{CH}_{2}\right]$ human insulin was formed (XII). Importantly, no oxidation of the thioether moiety to the sulfoxide was detected. A yield of $25 \%$ for the final step was 

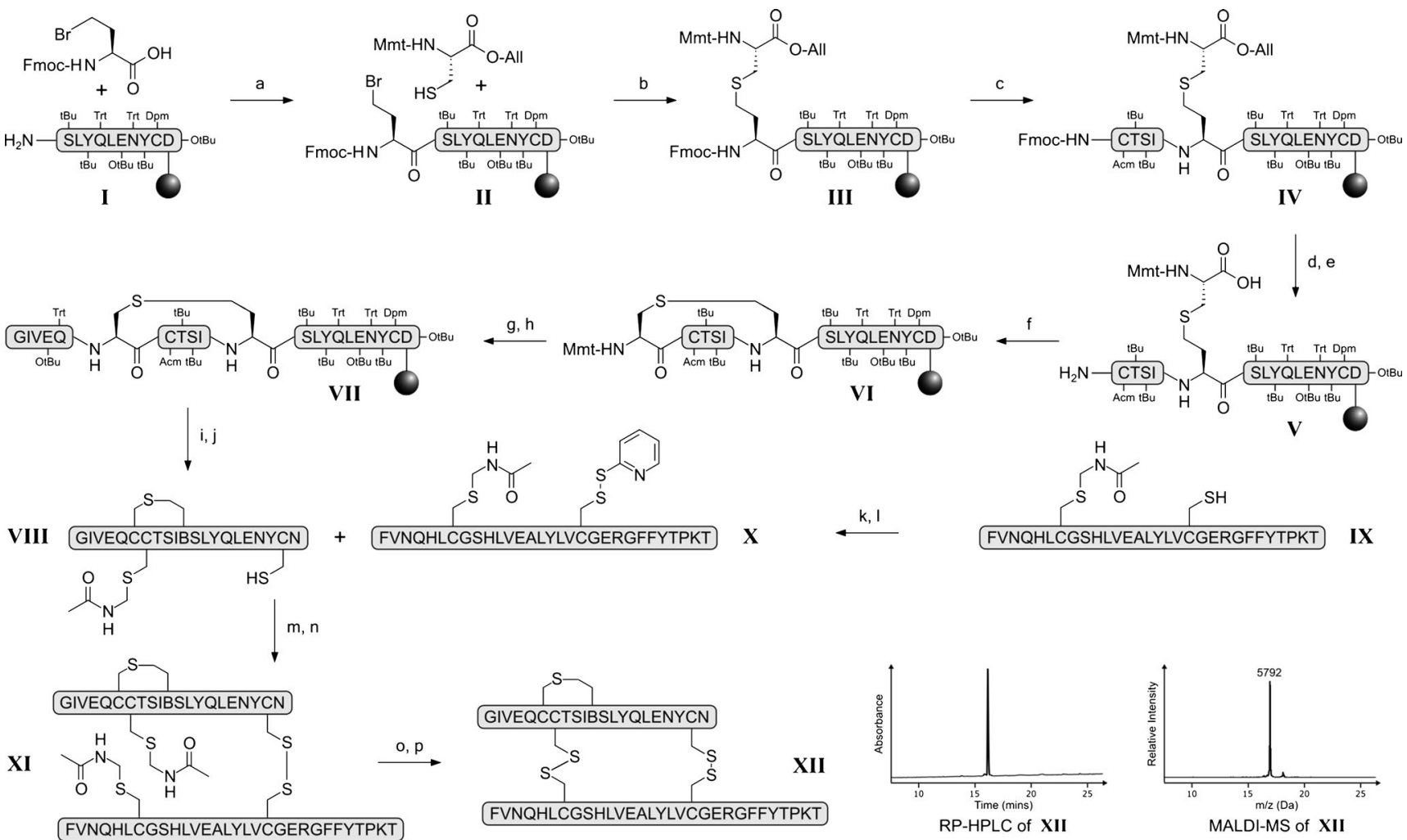

Scheme 2. Reagents and conditions: a) 3 equiv. Fmoc- $\gamma$-Br-hAla-OH/HOBt/DIC in DMF, 1 h; b) 5 equiv. Mmt-Cys-OAll, 10 equiv. DIEA in DMF, $3 \mathrm{~h}$; c) Fmoc SPPS; d) 3 equiv. $\mathrm{Pd}\left(\mathrm{PPh}_{3}\right)_{4}$ in $2.5 \% \mathrm{NMM} / 5 \% \mathrm{AcOH} / 92.5 \% \mathrm{CHCl}_{3}, 3 \mathrm{~h}$; e) $20 \%$ piperidine in DMF, $10 \mathrm{~m}$; f) 5 equiv. $\mathrm{HOBt} / \mathrm{DIC}$, $3 \mathrm{~h}$; g) $1 \%$ TFA in DCM, $10 \times 5$ m; h) Fmoc SPPS; i) $1 \%$ TIPS/2\% $\mathrm{H}_{2} \mathrm{O} / 2 \%$ DODT/95\% TFA, 3 h; j) RP-HPLC; $k$ ) 5 equiv. DPDS in TFA, 1 h; l) RP-HPLC; m) 6 M guanidinium hydrochloride, $\mathrm{pH} 8,1 \mathrm{~h}$; n) RP-HPLC; o) 20 equiv. $\mathrm{I}_{2}$ in AcOH, 1 h; p) RP-HPLC. Fmoc $=9$-fluorenylmethyloxycarbonyl; Mmt =mono-methoxytrityl; $t \mathrm{Bu}=$ tert-butyl; Trt = trityl; $\mathrm{Dpm}=$ diphenylmethyl; $\mathrm{Acm}=$ acetamidomethyl; O-All $=\mathrm{O}-\mathrm{allyl} ; \mathrm{HOBt}=$ 1-hydroxybenzotriazole; $\mathrm{DIC}=$ diisopropylcarbodiimide; $\mathrm{DMF}=$ dimethylformamide; $\mathrm{NMM}=\mathrm{N}$-methylmorpholine; TIPS =triisopropylsilane; DODT $=3,6$-dioxa-1,8-octane-dithiol; DPDS $=2,2^{\prime}$-dipyridyl disulfide.

determined post-purification and the total folding yield as calculated from purified B-chain was $11 \%$. Synthetic A[S$\mathrm{CH}_{2}$ ] human insulin was characterized via analytical RPHPLC and MALDI-MS. The purity was determined to be $>96 \%$ and the molecular mass was measured to be $5792 \mathrm{Da}$ $\left(\left[M+\mathrm{H}^{+}\right]^{+}{ }_{\text {th. }}=5791\right)$. See the Supporting Information for detailed characterization.

$\mathrm{A}\left[\mathrm{S}-\mathrm{CH}_{2}\right]$ human insulin had the same binding affinity as the native hormone for the insulin receptor isoform $\mathrm{B}$ (IR-B) (Figure 2A). ${ }^{[36]}$ This indicates that the tertiary structure is largely unchanged despite the substitution of intra-A-chain cystine with cystathionine. This is supported by the close similarity of the circular dichroism (CD) spectra (Figure 2B) and ${ }^{1} \mathrm{H}$ NMR spectra (see the Supporting Information) of both the analogue and native insulin. The proportion of $\alpha$ helicity ${ }^{[37]}$ was, therefore, calculated to be approximately the same (see the Supporting Information). The in vitro plasma stability of $\mathrm{A}\left[\mathrm{S}-\mathrm{CH}_{2}\right]$ human insulin in human serum was maintained after 24 hours (Figure $3 \mathrm{~A}$ ). This is important because even minor modifications of peptides and proteins can render them unstable as slight conformational changes can expose sensitive amide linkages to proteases. ${ }^{[38]}$ Both the analogue and native insulin were also incubated at $60^{\circ} \mathrm{C}$ for 4 days in $\mathrm{H}_{2} \mathrm{O}$. The thermal stability of the analogue was significantly increased as shown at day $4(p<0.05)$. The native hormone had degraded by almost $70 \%$ while $\mathrm{A}\left[\mathrm{S}-\mathrm{CH}_{2}\right]$ human insulin was correspondingly degraded to an extent of approximately $10 \%$ (Figure $3 \mathrm{~B}$ ). Further evaluation is required, such as in vivo testing, determination of the heat stability of hexameric forms of the new analogue and tertiary structure elucidation. That $\mathrm{A}\left[\mathrm{S}-\mathrm{CH}_{2}\right]$ human insulin retains native insulin activity and possesses significant stability against chemical degradation suggests its potential for further development as a therapeutic for type 1 diabetics in developing countries.

In summary, an improved methodology for the efficient solid phase synthesis of cystathionine-containing peptides has been developed. This was achieved using Fmoc SPPScompatible, orthogonally-protected monomeric building blocks that can be produced in good yield. This strategy was successfully applied to the synthesis of human insulin by incorporating the thioether moiety in place of the A6-A11 cystine bridge followed by formation of the interchain disulfide bonds. For this approach, the "directionality" of the cystathionine bridge can be reversed by incorporating $\beta$ bromoalaninyl and homocysteinyl based building blocks instead. This methodology can be readily applied to other cystine-rich peptides and proteins. 

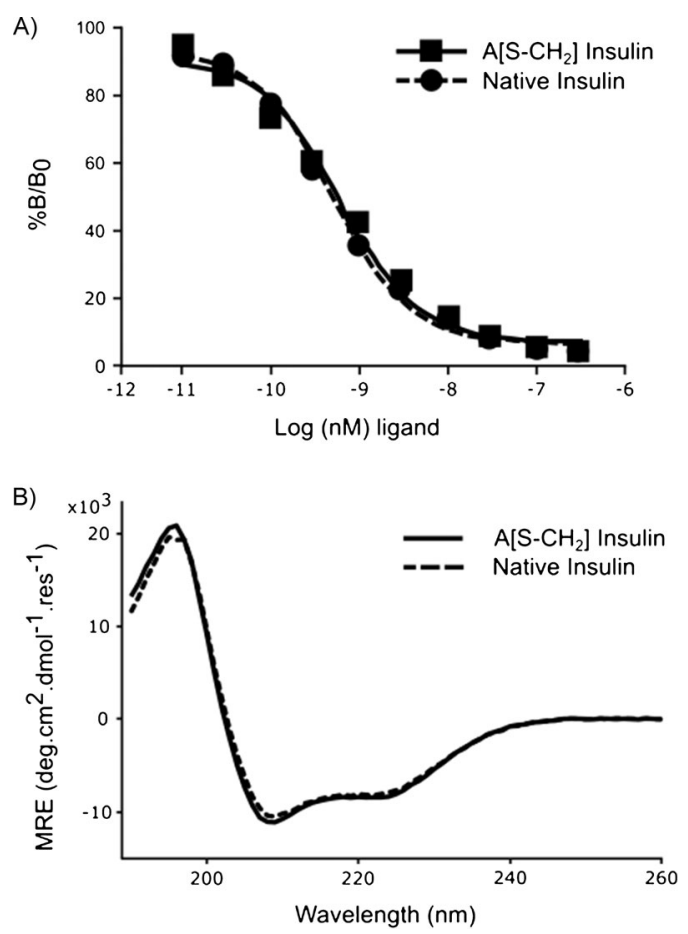

Figure 2. A) Insulin receptor binding assay (isoform B) for $\mathrm{A}\left[\mathrm{S}-\mathrm{CH}_{2}\right]$ human insulin $\left(I_{50}=6.217 \mathrm{e}^{-10}\right)$ and native insulin $\left(I_{50}=4.950 \mathrm{e}^{-10}\right)$, $n=3$. B) Circular dichroism spectra of $\mathrm{A}\left[\mathrm{S}-\mathrm{CH}_{2}\right]$ human insulin and native human insulin in $\mathrm{H}_{2} \mathrm{O}$ at $25^{\circ} \mathrm{C}$.

A)
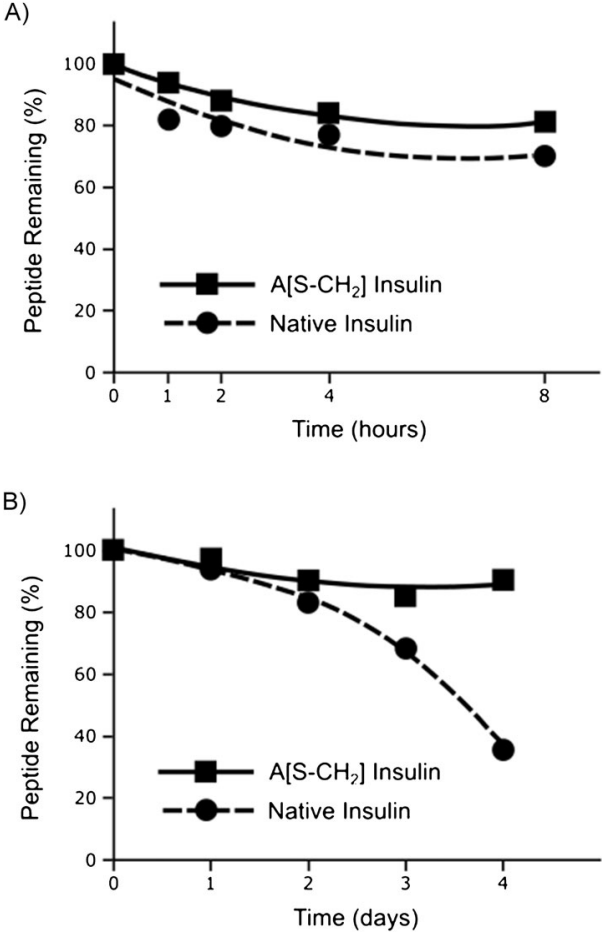

Figure 3. A) Serum stability assay of $\mathrm{A}\left[\mathrm{S}-\mathrm{CH}_{2}\right]$ and native human insulins at $37^{\circ} \mathrm{C}$. B) Thermal stability of $\mathrm{A}\left[\mathrm{S}-\mathrm{CH}_{2}\right]$ and native insulins in $\mathrm{H}_{2} \mathrm{O}$ at $60^{\circ} \mathrm{C}$.

\section{Acknowledgements}

This research was partially funded by the NHMRC Project grants 1023321 and 1023078 to M.A.H. and J.D.W., the CSIRO (Australia), a Florey Foundation Fellowship to M.A.H., and an NHMRC Principal Research Fellowship to J.D.W. (GNT5018148). Research at The Florey Institute of Neuroscience and Mental Health is supported by the Victorian Government Operational Infrastructure Support Program. The publication of this manuscript was supported by the David Lachlan Hay Memorial Fund (University of Melbourne).

Keywords: cystathionine $\cdot$ cystine $\cdot$ diabetes mellitus $\cdot$ insulin solid-phase peptide synthesis

[1] IDF Diabetes Atlas, 6th ed., International Diabetes Federation, 2013.

[2] A. Cahn, R. Miccoli, A. Dardano, S. Del Prato, Lancet Diabetes Endocrinol. 2015, 3, 638-652.

[3] R. J. Woods, J. Alarcón, E. McVey, R. J. Pettis, J. Diabetes Sci. Technol. 2012, 6, $265-276$.

[4] J. Brange, L. Langkjær, S. Havelund, A. Vølund, Pharm. Res. 1992, 9, 715-726.

[5] J. Brange, S. Havelund, P. Hougaard, Pharm. Res. 1992, 9, $727-$ 734.

[6] M. Weiss, J. Health Spec. 2013, 1, 59.

[7] Q.-X. Hua, S. H. Nakagawa, W. Jia, K. Huang, N. B. Phillips, S.Q. Hu, M. A. Weiss, J. Biol. Chem. 2008, 283, 14703-14716.

[8] T. N. Vinther, M. Norrman, U. Ribel, K. Huus, M. Schlein, D. B. Steensgaard, T. Å. Pedersen, I. Pettersson, S. Ludvigsen, T. Kjeldsen et al., Protein Sci. 2013, 22, 296-305.

[9] K. Jošt, J. Rudinger, H. Klostermeyer, H. Zahn, Z. Naturforschung B 1968, 23, 1059-1061.

[10] G. M. Williams, K. Lee, X. Li, G. J. S. Cooper, M. A. Brimble, Org. Biomol. Chem. 2015, 13, 4059-4063.

[11] A. Dantas de Araujo, M. Mobli, J. Castro, A. M. Harrington, I. Vetter, Z. Dekan, M. Muttenhaler, J. Wan, R. J. Lewis, G. F. King et al., Nat. Commun. 2014, 5, 3165.

[12] E. P. Kroeff, R. A. Owens, E. L. Campbell, R. D. Johnson, H. I. Marks, J. Chromatogr. 1989, 461, 45-61.

[13] K. C. Mulder, A. A. Viana, M. Xavier, N. S. Parachin, Curr. Protein Pept. Sci. 2013, 14, 556-567.

[14] C. J. Armishaw, N. L. Daly, S. T. Nevin, D. J. Adams, D. J. Craik, P. F. Alewood, J. Biol. Chem. 2006, 281, 14136-14143.

[15] K. Holland-Nell, M. Meldal, Angew. Chem. Int. Ed. 2011, 50, 5204-5206; Angew. Chem. 2011, 123, 5310-5312.

[16] M. Empting, O. Avrutina, R. Meusinger, S. Fabritz, M. Reinwarth, M. Biesalski, S. Voigt, G. Buntkowsky, H. Kolmar, Angew. Chem. Int. Ed. 2011, 50, 5207-5211; Angew. Chem. 2011, 123, $5313-5317$.

[17] A. Gori, C.-I. A. Wang, P. J. Harvey, K. J. Rosengren, R. F. Bhola, M. L. Gelmi, R. Longhi, M. J. Christie, R. J. Lewis, P. F. Alewood et al., Angew. Chem. Int. Ed. 2015, 54, 1361-1364; Angew. Chem. 2015, 127, 1378-1381.

[18] E. E. Büllesbach, C. Schwabe, Biochemistry 2012, 51, 4198 4205.

[19] J. Karas, F. Shabanpoor, M. A. Hossain, J. Gardiner, F. Separovic, J. D. Wade, D. B. Scanlon, Int. J. Pept. 2013, 2013, 1-8.

[20] M. A. Hossain, K. J. Rosengren, S. Zhang, R. A. D. Bathgate, G. W. Tregear, B. J. van Lierop, A. J. Robinson, J. D. Wade, Org. Biomol. Chem. 2009, 7, 1547. 
[21] S. Zhang, R. A. Hughes, R. A. D. Bathgate, F. Shabanpoor, M. A. Hossain, F. Lin, B. van Lierop, A. J. Robinson, J. D. Wade, Peptides 2010, 31, 1730-1736.

[22] H.-K. Cui, Y. Guo, Y. He, F.-L. Wang, H.-N. Chang, Y.-J. Wang, F.-M. Wu, C.-L. Tian, L. Liu, Angew. Chem. Int. Ed. 2013, 52 , 9558-9562; Angew. Chem. 2013, 125, 9737-9741.

[23] P. J. Knerr, A. Tzekou, D. Ricklin, H. Qu, H. Chen, W. A. van der Donk, J. D. Lambris, Chem. Biol. 2011, 6, 753-760.

[24] Z. Dekan, I. Vetter, N. L. Daly, D. J. Craik, R. J. Lewis, P. F Alewood, J. Am. Chem. Soc. 2011, 133, 15866-15869.

[25] A. K. Galande, J. O. Trent, A. F. Spatola, Pept. Sci. 2003, 71, $534-551$.

[26] J. P. Mayer, J. R. Heil, J. Zhang, M. C. Munson, Tetrahedron Lett. 1995, 36, 7387-7390.

[27] K. Jošt, J. Rudinger, Amino Acids Pept. LXXIV 1967, 32, 2485 2490.

[28] J. Rudinger, K. Jošt, Experientia 1964, 20, 570-571.

[29] Y. Rew, S. Malkmus, C. Svensson, T. L. Yaksh, N. N. Chung, P. W. Schiller, J. A. Cassel, R. N. DeHaven, M. Goodman, J. Med. Chem. 2002, 45, 3746-3754.

[30] J. R. Harjani, B. K. Yap, R. S. Norton, J. B. Baell, Tetrahedron 2016, 72, 3256-3261.
[31] K. Akaji, K. Fujino, T. Tatsumi, Y. Kiso, J. Am. Chem. Soc. 1993, 115, 11384-11392.

[32] M. Góngora-Benítez, L. Mendive-Tapia, I. Ramos-Tomillero, A. C. Breman, J. Tulla-Puche, F. Albericio, Org. Lett. 2012, 14, $5472-5475$.

[33] H. Kunz, H. Waldmann, C. Unverzagt, Int. J. Pept. Protein Res. 1985, 26, 493-497.

[34] G. M. Dubowchik, S. Radia, Tetrahedron Lett. 1997, 38, 52575260.

[35] K. Akaji, Y. Kiso, Houben-Weyl Synth. Pept. Pept., Thieme, Stuttgart, 2002, pp. $101-141$.

[36] A. Denley, C. C. Wang, K. A. McNeil, M. J. E. Walenkamp, H. van Duyvenvoorde, J. M. Wit, J. C. Wallace, R. S. Norton, M. Karperien, B. E. Forbes, Mol. Endocrinol. 2005, 19, 711-721.

[37] L. V. Najbar, D. J. Craik, J. D. Wade, D. Salvatore, M. J. McLeish, Biochemistry 1997, 36, $11525-11533$.

[38] M. A. Hossain, L. M. Haugaard-Kedström, K. J. Rosengren, R. A. D. Bathgate, J. D. Wade, Org. Biomol. Chem. 2015, 13, $10895-10903$.

Received: July 22, 2016

Published online: 


\section{Communications}

Insulin Derivatives

J. A. Karas, N. A. Patil, J. Tailhades, M.-A. Sani, D. B. Scanlon, B. E. Forbes, J. Gardiner, F. Separovic, J. D. Wade,* M. A. Hossain* III-III

Total Chemical Synthesis of an Intra-AChain Cystathionine Human Insulin Analogue with Enhanced Thermal

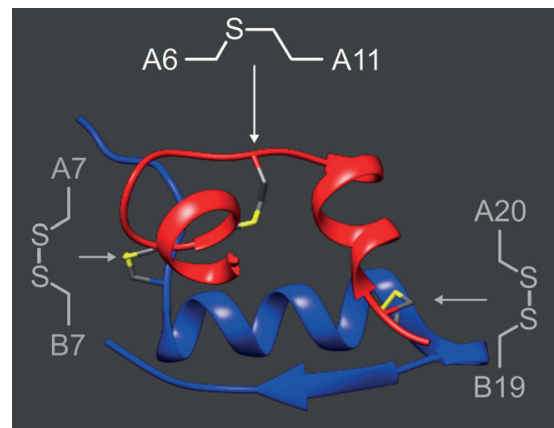

Standing the heat: An efficient synthesis of human insulin containing a nonreducible cystathionine bridge using simple-to-prepare building blocks is reported. $\mathrm{A}\left[\mathrm{S}-\mathrm{CH}_{2}\right]$ insulin exhibits native binding affinity for insulin receptor isoform B, adopts a similar secondary structure and is relatively stable in human serum in vitro. Thermal stability is improved which enhances its therapeutic potential. 